\title{
Imaging Genomics and Response to Treatment with Antipsychotics in Schizophrenia
}

\author{
Giuseppe Blasi*广 and Alessandro Bertolino*广† \\ *Psychiatric Neuroscience Group, Department of Neurological and Psychiatric Sciences, University of Bari, Bari, Italy 70125; \\ ${ }^{\dagger}$ Clinical Brain Disorders Branch, Gene, Cognition and Psychosis Program, National Institute of Mental Health, National \\ Institutes of Health, Bethesda, MD 20892; and "Department of Neuroradiology, IRCCSS “Casa Sollievo della Sofferenza,” \\ San Giovanni Rotondo, Italy 71013
}

\begin{abstract}
Recent important advancements in genomic research have opened the way to new strategies for public health management. One of these questions pertains to how individual genetic variation may be associated with individual variability in response to drug treatment. The field of pharmacogenetics may have a profound impact on treatment of complex psychiatric disorders like schizophrenia. However, pharmacogenetic studies in schizophrenia have produced conflicting results. The first studies examined potential associations between clinical response and drug receptor genes. Subsequent studies have tried to use more objective phenotypes still in association with drug receptor genes. More recently, other studies have sought the association between putative causative or modifier genes and intermediate phenotypes. Thus, conflicting results may be at least in part explained by
\end{abstract}

variability and choice of the phenotype, by choice of candidate genes, or by the relatively little knowledge about the neurobiology of this disorder. We propose that choosing intermediate phenotypes that allow in vivo measurement of specific neuronal functions may be of great help in reducing several of the potential confounds intrinsic to clinical measurements. Functional neuroimaging is ideally suited to address several of these potential confounds, and it may represent a powerful strategy to investigate the relationship between behavior, brain function, genes, and individual variability in the response to treatment with antipsychotic drugs in schizophrenia. Preliminary evidence with potential susceptilibity genes such as COMT, DISC1, and GRM3 support these assumptions. Key Words: Imaging genomics, antipsychotics, schizophrenia, fMRI, PET, COMT, DISC1, GRM3.

\section{INTRODUCTION}

The recent mapping of the human genome has prompted a new series of questions that include the function of individual genes at the level of brain physiology and the contribution of genetic factors to susceptibility to psychiatric disorders and on their related neurobiology. Within the framework of these questions, recent studies are beginning to explain the relationship between genes, neurons, brain networks, and behavior, as well as to shed light on the basis of the individual variability related to this relationship. Because schizophrenia is a brain disease whose susceptibility is largely genetic, ${ }^{1}$ it is clear that research following this approach might be particularly fruitful both in terms of discovering the etiology as well as the pathophysiology of this disorder. Moreover,

Address correspondence and reprint requests to Alessandro Bertolino, M.D., Ph.D., Dipartimento di Scienze Neurologiche e Psichiatriche, Universita' degli Studi di Bari, Piazza Giulio Cesare 9, 70124 Bari, Italy.E-mail: bertolia@psichiat.uniba.it. this theoretical approach has operative implications that might lead to more precise knowledge on the bases of individual variability in response to treatment with antipsychotic drugs.

In this context, single-nucleotide polymorphisms (SNPs), i.e., nucleotide variants in specific locations of gene sequence, are assuming specific relevance, particularly if they have functional consequences for the proteins that they code for. Functional SNPs modify the structure and/or function of the protein so that its activity varies as a function of the allelic variant present in each individual. These variations of the protein might differentially impact on brain physiology, behavior, and pathophysiology, thus contributing to susceptibility for schizophrenia and to modulate individual responses to pharmacological treatment with antipsychotics.

Current brain imaging techniques provide novel tools to study more specifically the relationship between behavior, pathophysiology, genetics, and treatment. Behavior is sustained by relatively specific brain activity that is 

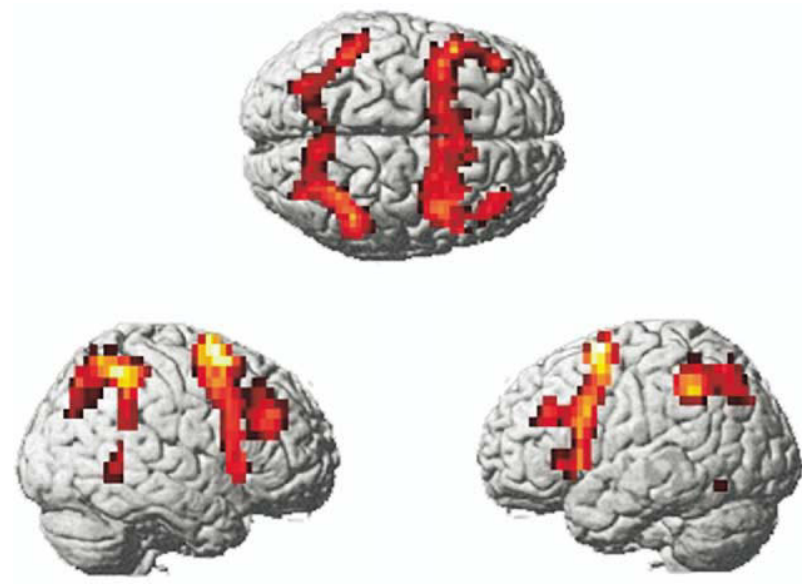

FIG. 1. fMRI statistical map (sagittal and axial three-dimensional renderings) showing parietal and dorsolateral prefrontal cortical (DLPFC) activation during performance of a working memory task (N-BACK) in a group of healthy subjects.

measurable with different techniques such as fMRI [functional MRI (magnetic resonance imaging)] (FIG. 1) and positron emission tomography (PET). The major contribution of these techniques is that they permit the creation and analysis of statistical maps of brain activity in single subjects as well as in group of individuals. Thus, functional brain imaging allows statistical exploration of the main effect of genes at the brain systems level during specific behaviors. Furthermore, once the physiological effect of genetic variants is known, the effect of the same genetic variants can be measured in brain disorders. As a further level of complexity, longitudinal studies with these techniques can assess the effects of pharmacological treatment. Integration of genetic, neuroimaging, and behavioral data can therefore bring to a further and more informative level of complexity the study on the interaction between genetic variants and antipsychotic treatment, potentially contributing more precisely tailored information about individuality of response to treatment.

The objective of the present paper is to review recent findings relative to the emerging relationship between genes, brain activity, behavior, and response to treatment with antipsychotics in schizophrenia.

\section{GENES, BRAIN ACTIVITY, AND BEHAVIOR IN SCHIZOPHRENIA}

Family and twin studies have indicated that the lion's share of susceptibility to schizophrenia is explained by genetic factors-approximately $80 \%{ }^{1}$ However, we are far from understanding how genes qualitatively and quantitatively influence the neurobiology of this disorder. Data from family studies suggest that the interaction of multiple genes, each with small effect, is more likely to explain risk for schizophrenia rather than a single causative gene. ${ }^{2}$ Previous studies have reported genetic linkage between schizophrenia and loci in 5q, 3p, 11q, $2 q, 1 q, 6 p, 20 p, 14 q 13 q,{ }^{3} 22 q$, and $8 p,{ }^{3,4}$ even if the results have not always been easy to replicate. However, the heterogeneity of the findings and of the clinical phenotype as well as the above mentioned concept that schizophrenia is more likely a polygenic complex disorder make it difficult to understand if and how these genetic loci are involved in its etiology or pathophysiology because genetic linkage is only based on statistics. ${ }^{2}$ These issues are even more evident because the association between genes and behavior or physiology of the CNS is not clearly understood, making it difficult to bridge the gap between genotype and phenotype. The operative concept of "intermediate phenotype" might help fill this gap. Intermediate phenotypes are represented by any measurable and reproducible cognitive or neurobiological phenomenon with relatively lower levels of complexity, possibly explained by the effect of one or few genes. In this review, we will mainly focus on the genes that have been shown to have a specific impact on intermediate or clinical phenotypes related to schizophrenia, basing our selection on statistical considerations, on the relevance of the relationship between genetics and behavior, and on the belief that the association between behavior or physiology and genes may strengthen the results supporting the association between genes of small effect and schizophrenia.

Given the known participation of dopamine in the pathophysiology of schizophrenia, the catechol-O-methyltransferase (COMT) gene has been repeatedly studied. COMT catalyzes the methylation of catecholamines such as dopamine and norepinephrine. Converging evidence indicates that methylation by COMT is an important mechanism for cortical dopamine inactivation in the prefrontal cortex, a region prominently involved in the pathophysiology of schizophrenia and its cognitive deficits (working memory and attention). ${ }^{5}$ Moreover, the dopamine transporter has relatively little synaptic density in prefrontal cortex..$^{6-8}$ Pharmacological COMT inhibitors, which increase extracellular dopamine in prefrontal cortex (PFC), ${ }^{9}$ also improve working memory performance $^{10}$ and attentional set shifting ${ }^{9}$ in rodents. Similarly, studies in COMT knockout mice have shown allele load-dependent specific increases in PFC dopamine levels and no change in other catecholamines. ${ }^{11}$ The COMT gene maps to the long arm of chromosome 22 (22q11), a region identified in several schizophrenia genome scan linkage studies. It contains a guanine-adenosine singlenucleotide polymorphism with a valine (val)-methionine (met) substitution at codon 158 in the protein. ${ }^{12}$ The val variant is more functionally active than the met variant. Therefore, the val allele is possibly associated with greater dopamine catabolism and reduced dopamine levels in prefrontal cortex. Furthermore, dopamine modu- 
lates glutamatergic and GABAergic signaling in prefrontal cortex,${ }^{13}$ and convergent findings suggest that optimal dopamine levels are key for its physiology during cognition. ${ }^{13,14}$ Consistent with these notions, it was logical to hypothesize that different COMT alleles of this polymorphism may be associated with differential behavior involving prefrontal cortex activity. Results from studies in humans seem to confirm this hypothesis. Egan et al. ${ }^{15}$ measured working memory and executive function performance with the Wisconsin Card Sorting Test in 175 patients with schizophrenia, 219 unaffected siblings, and 55 healthy subjects. Irrespective of diagnosis, val homozygotes had reduced behavioral accuracy relative to heterozygotes and met homozygotes. These findings were replicated in a subsequent study using the N-BACK task (measuring working memory) in a sample of 68 healthy subjects, 74 patients with schizophrenia, and 108 healthy siblings of patients with schizophrenia. ${ }^{16}$ Blasi et al. ${ }^{17}$ also found similar COMT genotype effects in healthy subjects performing a task measuring attentional control processing. Further studies in other patient populations have also been consistent. Bearden et al. ${ }^{18}$ showed better performance to tests measuring executive function in met subjects with 22q11.2 deletion syndrome relative to val subjects. Diamond et al. ${ }^{19}$ also found reduced behavioral performance in children homozygous for the val allele $(n=14)$ compared with heterozygotes $(n=16)$ and homozygotes for the met allele $(n=9)$ to a task thought to involve dopamine modulation of prefrontal cortex function.

Prefrontal cortical dysfunction during working memory and attention has been demonstrated. Recent studies with fMRI have reported that prefrontal dysfunction in schizophrenia may be evident as inefficiency in the physiology of processing of cognitive stimuli (greater prefrontal activity for similar or reduced behavioral accuracy). ${ }^{20,21}$ Some studies have also reported that COMT val ${ }^{158}$ met genotype affects brain physiology during cognition. Using fMRI, Egan et al. ${ }^{15}$ demonstrated greater dorsolateral prefrontal cortex activity during the N-BACK task in val relative to valmet subjects who, in turn, had greater activation relative to met homozygous, in spite of reduced behavioral accuracy. Blasi et al. ${ }^{17}$ also reported a similar effect of COMT on activity of the dorsal cingulate during a task providing increasing levels of attentional control processing. Analogous data of greater cortical activity during cognitive tasks associated with the val allele have been reported by Bertolino et al. ${ }^{22}$ and Ho et al. ${ }^{23}$ in patients with schizophrenia. These findings in healthy subjects, in patients with schizophrenia, and in their unaffected siblings suggest that inefficient prefrontal processing (greater activity for similar or reduced behavioral accuracy) during different cognitive processes is associated with the val allele, possibly related to decreased cortical dopamine levels. All these data are also substantiated by the possibility that the val allele seems to be overtransmitted in schizophrenia increasing risk with a small effect. ${ }^{2}$

The evidence for DISC1 being a putative causative gene for schizophrenia first appeared when St. Clair et al. ${ }^{24}$ demonstrated genetic linkage between major psychiatric illness and a balanced translocation of $1 \mathrm{q} 42.1$ (where DISC1 is mapped) and 11q14.3 in a Scottish family. Although no additional families with this translocation have been reported, a series of linkage and association studies in samples of patients with schizophrenia has reinforced the possible role of this gene, even though not always convincingly. ${ }^{25-30}$ The functional role of the DISC1 protein is not known yet. Earlier studies have demonstrated its interaction with cytoskeletal proteins like NUDEL and have speculated about its possible involvement in neurite outgrowth. ${ }^{31,32}$ Furthermore, the expression of this gene is prominent in the hippocampus, another region thought to be importantly involved in the pathophysiology of schizophrenia. A more recent study, ${ }^{33}$ using a sample of 801 subjects (252 patients with schizophrenia, 311 of their siblings, 238 healthy subjects), showed an association between a common nonconservative SNP (rs821616, a serine to cysteine substitution at codon 704) in the DISC1 gene and schizophrenia, with the serine allele being overtransmitted in patients. Furthermore, the allelic variants of this SNP differentially affected brain activity and metabolism as well as cognitive performance. In particular, the serine allele was associated with abnormal hippocampal activity during working memory and long-term memory, with reduced hippocampal gray matter volume, with reduced hippocampal $\mathrm{N}$-acetylaspartate (a marker of neuronal functional integrity) levels, and with impaired executive function and logical memory.

The GRM3 gene (mapped to 7q21.1) has been considered a putative causative gene for schizophrenia consistent with the possible role of glutamate in the pathophysiology of this disorder..$^{34,35-37}$ GRM3 encodes for a metabotropic glutamate receptor. ${ }^{38}$ In astroglial cells, GRM3 regulates the expression of the glial glutamate transporter, EAAT2, ${ }^{39}$ a critical regulator of synaptic glutamate activity. ${ }^{40}$ Studies in animal models with GRM3 agonists have demonstrated reduction of psychosis-like behaviors induced by ketamine. ${ }^{41}$ Postmortem studies have reported reduction of GRM3 mRNA levels in patients with schizophrenia. ${ }^{42}$ Moreover, the GRM3 gene has been previously associated with schizophrenia. ${ }^{43-45}$ Fujii et al. ${ }^{44}$ found a significant difference in GRM3 SNP rs1468412 allele frequencies between patients with schizophrenia and healthy subjects. Moreover, a haplotype constructed from three SNPs, including rs1468412, showed a significant association with schizophrenia. Egan et al. ${ }^{43}$ reported overtransmission of the adenine allele of an intronic SNP (hCV11245618) in patients with schizophrenia within families. Moreover, 
this allele was associated with: reduced in vivo prefrontal $\mathrm{N}$-acetylaspartate measures (a marker of neuronal integrity measured with in vivo ${ }^{1} \mathrm{H}$ magnetic resonance spectroscopy and repeatedly found to be reduced in schizophrenia) $)^{46}$; reduced EAAT2 mRNA levels in postmortem tissue; reduced cognitive performance in verbal list learning and verbal fluency tasks; inefficient activation of the dorsolateral prefrontal cortex activation during working memory (as measured by fMRI); and reduced hippocampal activation during encoding of an episodic memory task (suggesting an abnormal physiological response). However, other studies have reported weak associations or have not replicated the association between GRM3 and schizophrenia. ${ }^{47,48}$

Brain-derived neurotrophic factor (BDNF) is one of the most studied member of the family of neurotrophins. Data from animal models suggest that this protein facilitates both neurotransmission and hippocampal longterm potentiation ${ }^{49,50}$ by increasing high-frequency synaptic transmission and improving synaptic vesicle docking. ${ }^{51-55}$ Moreover, experiments in rodents have demonstrated that BDNF signaling is crucial for several cognitive processes, including spatial learning and memory performance. ${ }^{56-58}$ Given the relationship between BDNF and hippocampal function, between reduced cortical and hippocampal levels of BDNF and schizophrenia, ${ }^{59}$ and between hippocampal biochemistry and genetic risk for schizophrenia, ${ }^{60}$ several studies in schizophrenia have investigated the possible role of BDNF, (mapped to 11p13) with variable results. ${ }^{61-67}$ To further explore this association, Egan et al. ${ }^{64}$ studied with a multimodal approach the effect of a BDNF coding SNP [guanine/adenosine polymorphism at position 196 in the $5^{\prime}$ pro-BDNF sequence, producing a valine to methionine substitution in the immature protein ( $\left.\left.\mathrm{val}^{66} \mathrm{met}\right)\right]$, in a large sample of healthy subjects, patients with schizophrenia, and their healthy siblings. Although the authors did not find a statistical association between BDNF and schizophrenia, they demonstrated in living subjects that the met allele was associated with lower episodic memory performance, abnormal hippocampal activity as measured by fMRI, reduced hippocampal $\mathrm{N}$-acetylaspartate as assessed by magnetic resonance spectroscopic imaging, and in cell culture, altered intracellular localization and reduced stimulus-evoked release of BDNF. Similar results on the effect of this BDNF polymorphism on hippocampal activity and volume have been reported in other studies in healthy subjects. ${ }^{68,69}$ Furthermore, Szeszko et al. ${ }^{70}$ showed reduced hippocampal volume in met-carriers of a mixed sample of patients with schizophrenia and healthy subjects. Moreover, they reported that $\mathrm{val}^{66}$ met genotype accounted for greater proportion of the variance for hippocampal formation volume in patients than in healthy subjects. In summary, there is evidence suggesting that the BDNF gene affects hip- pocampal function and that it may be a modifying genetic factor in the expression of brain phenotypes in schizophrenia.

These various examples illustrate how neuroimagingbased phenotyping has allowed clarification of the role of potential schizophrenia susceptibility genes on brain structure and function. The question next arises as to whether these genes also have an effect on modification of specific behaviors in response to treatment with antipsychotic drugs.

\section{GENES, BEHAVIOR, AND ANTIPSYCHOTIC TREATMENT IN SCHIZOPHRENIA}

The majority of pharmacogenetic studies related to antipsychotic drug treatment to date have focused on genes coding for serotonine and dopamine receptors because they are the target for antipsychotic drugs. For example, some of these studies have evaluated various $5 \mathrm{HT}_{2 \mathrm{~A}}$ gene polymorphisms in response to treatment with clozapine. In particular, the $\mathrm{His}^{452} \mathrm{Tyr}, \mathrm{T} 102 \mathrm{C}$ $5 \mathrm{HT}_{2 \mathrm{~A}}$, and $-1438 \mathrm{G} / \mathrm{A} 5 \mathrm{HT}_{2 \mathrm{~A}}$ gene polymorphisms have been the subject of several studies, with conflicting results. ${ }^{71}$ Other studies on dopamine receptor genes have focused mainly on $\mathrm{D}_{2}$ and $\mathrm{D}_{4}$ polymorphisms, in particular on the $\mathrm{D}_{2}$ Taq1A and the $-141 \mathrm{C}$ Ins/Del variants, generally showing a possible effect of $\mathrm{D}_{2}$ receptor polymorphisms on determining clinical response to antipsychotic treatment. ${ }^{72-76}$ All of these studies have been carefully reviewed elsewhere. $^{71}$

In contrast, few published studies have addressed whether individual variability of changes in cognitive behavior associated with antipsychotic treatment is differentially affected by putative causative genes. Two studies have addressed this point relative to COMT $\mathrm{val}^{158}$ met genotype. Bertolino et al. ${ }^{22}$ analyzed the effect of COMT val ${ }^{158}$ met genotype on response to antipsychotic treatment with olanzapine (a second-generation antipsychotic drug that increases dopamine levels in prefrontal cortex). ${ }^{77}$ Using a sample of 30 patients with schizophrenia, the authors demonstrated that met homozygotes benefit more from olanzapine treatment than valmet and valval subjects in terms of working memory performance and improvement in negative symptoms. Further details on this study will be given below (see also Diaz-Asper ${ }^{78}$ ). Weickert et al. ${ }^{79}$ showed similar results using 20 patients with schizophrenia and schizoaffective disorder (5 were val homozygous, 11 were heterozygotes, and 4 were met homozygous). These patients were studied twice, each at the end of two 4-week periods, one after treatment with first or second-generation antipsychotics and the other after treatment with placebo. To control for order effects, half of the subjects received placebo first, the other half antipsychotics first. Cognitive evaluation included working memory (N-BACK), executive function (Wiscon- 
sin Card Sorting Test), verbal fluency, general intelligence (WAIS-R), and general memory (Wechsler Memory Scale Revised, General Memory Index). The Positive and Negative Symptoms Scale (PANSS) was used to measure clinical symptoms. The working memory results indicated that val homozygous subjects performed significantly worse than met subjects, confirming previous results on the effect of COMT val ${ }^{158}$ met genotype. Additionally, an interaction between COMT val ${ }^{158}$ met genotype and treatment on working memory performance was found, i.e., met homozygous patients had greater improvement in accuracy after 4 weeks of antipsychotic treatment compared with the other two groups, valmet heterozygous, or val homozygous subjects. No interaction between COMT val ${ }^{158}$ met genotype and treatment was found on performance of the other cognitive domains and on PANSS scores.

One study focused on the impact of GRM3 variants on antipsychotic treatment. For 6 weeks, Bishop et al. ${ }^{80}$ treated 42 patients with schizophrenia with a fixed dose of olanzapine; the Brief Psychiatric Rating Scale (BPRS) and the Scale for Assessment of Negative Symptoms (SANS) were used for assessment of clinical symptoms at baseline and at end point. They found that several GRM3 polymorphisms collectively predicted negative symptoms improvement; and one SNP in particular (rs274622) showed greater effect on SANS scores, although its influence was not fully dissociable from those of the other polymorphisms typed.

Krebs et al., ${ }^{81}$ using a sample of 88 patients with schizophrenia or schizoaffective disorder, studied the impact of a dinucleotide repeat polymorphism in BDNF and response to treatment. This polymorphism is in incomplete linkage disequilibrium with the val/met coding SNP. They found increased frequency of long alleles (172-176 bp) in responders compared to nonresponder patients with schizophrenia. The authors defined responder patients as those who had at least partial remission under antipsychotic treatment allowing discharge from hospital. Nonresponder patients were defined as subjects without clinical remission even if treated with several trials of different antipsychotics. Hong et al. ${ }^{82}$ studied 93 patients with schizophrenia with the BPRS as an outcome measure, defining as responders those subjects who had at least a $20 \%$ decrease of BPRS score after at least 8 weeks of treatment with clozapine. They found no differences in the distribution of the BDNF $\mathrm{val}^{66}$ met genotype relative to response to clozapine treatment, although they did find increased frequency of the val allele in responders relative to 198 healthy subjects. Anttila et al., ${ }^{83}$ in a retrospective study on 94 patients with schizophrenia, failed to find any association between response to treatment with first-generation antipsychotics and either BDNF guanine ${ }^{196}$ adenosine or valine ${ }^{66}$ metionine polymorphisms. However, no rating scales were used because the study was retrospective; patients were defined as responders if they experienced sufficient and long-lasting response to treatment, whereas nonresponders were patients who failed to respond to at least two trials with different typical antipsychotics.

In summary, the above-cited studies show that pharmacogenetics might be helpful to explain at least part of the individual variability in clinical and cognitive/behavioral response to treatment with antipsychotics, but the studies are limited in many respects. However, partial reproducibility of the results suggests that the approach used in these studies may have limited potential for the understanding of the relationship between individual genetic factors and treatment response. In particular, some of the discordancy in results might be explained by the imprecise phenotypes chosen as outcome measures. The clinical phenotype of schizophrenia is highly complex and variable. Measurement of the clinical symptoms of schizophrenia is still based on subjective rating scales scores. Moreover, these scores may reflect an interaction between multiple psychopathological domains, making it highly unlikely that they can be explained by any single specific neurobiological mechanism. Therefore, it is also highly unlikely that they might be associated only to the effect of a single gene, making gene effects less detectable. Furthermore, some of these studies used retrospective methodologies, sometimes using qualitative and not quantitative outcome measures, thus increasing variance and decreasing the possibility of detecting effects of a single genetic factor. The relative lack of information about the neurobiology of genetic variants might also contribute to the uncertainty and inconsistency. Knowledge of the neurobiological effect of genetic polymorphisms is crucial to understand their possible implications for the pathophysiology of schizophrenia and the implications for treatment, directing data analysis toward more specific objectives and making the results more easily interpretable. Moreover, the relative lack of dependable, reliable, and reproducible physiological measures associated with the phenotype under investigation increases the uncertainly related to the findings in this field. This limitation is true for most brain disorders and imposes major problems when trying to evaluate variability in the response to drug treatment.

These limitations have prompted investigators to look for other phenotypes and they will be further discussed below.

\section{BRAIN PHYSIOLOGY, ANTIPSYCHOTIC TREATMENT, AND SCHIZOPHRENIA}

To further understand the possible relationship between genes, physiology, behavior, and treatment, it is useful to review some of the effects of treatment with antipsychotics on brain physiology. Several of these 
studies explored structural brain changes related to treatment. Corson et al. ${ }^{84}$ considered 23 male patients with schizophrenia spectrum disorders treated with either first or second-generation antipsychotics undergoing magnetic resonance imaging at admission and after 2 years of treatment. The results indicated that 2 years of treatment with first-generation antipsychotics increased basal ganglia volume, whereas treatment with second-generation antipsychotics reduced it. Scheepers et al. ${ }^{85}$ measured caudate volume in 26 patients with schizophrenia before and after 24 weeks of treatment with clozapine. All patients had been switched from first-generation antipsychotic drugs to clozapine treatment after 3 days of washout. The authors reported caudate volume reduction after clozapine treatment and no caudate volume difference between responders (at least 20\% reduction in PANSS score) and nonresponders to clozapine. However, in an extension of this study, ${ }^{86}$ reduction of the left caudate volume was found after 52 weeks of treatment only in responders to clozapine. Lang et al. ${ }^{87}$ studied a cohort of 30 first-episode and 12 chronically ill schizophrenia patients, along with 23 controls. All subjects were scanned with magnetic resonance imaging at baseline; first-episode patients were rescanned after 1 year of treatment with risperidone, and healthy subjects were rescanned after comparable time. The results showed that chronically ill patients presented reduced caudate, putamen, and globus pallidus volume compared with healthy subjects at baseline, whereas no difference was found between first-episode patients and controls. No difference between the latter two groups was also found at rescan. The same group of investigators ${ }^{88}$ also reported basal ganglia volume reduction after olanzapine treatment in 10 patients with schizophrenia previously treated with first-generation antipsychotics; in contrast, the latter treatment was associated with volume increase of these structures relative to healthy subjects. An effect of olanzapine treatment on basal ganglia volume was found after switch from risperidone in 13 subjects. Lieberman et al. ${ }^{89}$ in a large multicenter study including 161 first episode psychosis patients treated with either haloperidol $(n=79)$ or olanzapine $(n=82)$, compared gray matter volume at baseline and after 12, 24, 52, and 104 weeks of treatment. They found that haloperidol but not olanzapine treatment was associated with gray matter volume decreases diffusely throughout the cortex. A recent study has shown that chronic treatment with either olanzapine or haloperidol reduces cortical volume in monkeys. ${ }^{90}$

In summary, morphological studies with MRI have mostly tried to address volumetric changes related to antipsychotic treatment in the basal ganglia, generally reporting differential effect of first and second-generation antipsychotics. First-generation antipsychotics seem to increase, whereas second-generation antipsychotics seem to reduce volume of the basal ganglia. The opposite effect has been reported when measuring total cortical gray matter volume. However, from studies in nonhuman primates ${ }^{90}$ reporting substantial gray and white matter volume reductions after long-term treatment with haloperidol or olanzapine, it is clear that brain volumetric changes occur with antipsychotic treatment. The underlying mechanism is unclear, however. It is also possible that this issue will not be resolved in human studies, given the potential confounds usually associated with studying human samples with structural MRI. Another limitation of structural MRI studies is that the functional and metabolic correlates of these putative variations in morphology are not known.

Other methodologies like magnetic resonance spectroscopy (MRS), PET, and fMRI may be more informative. In particular, MRS affords measurement of brain chemicals considered markers of metabolic processes. Fukuzako et al. ${ }^{91}$ examined with ${ }^{31} \mathrm{P}$-MRS 13 patients with schizophrenia before and after treatment with haloperidol reporting higher levels of phosphodiesters only before treatment in temporal lobes compared with healthy controls. Treatment with haloperidol tended to reduce phosphodiesters increases in patients and these changes were also correlated with symptom reduction. The authors suggested that haloperidol may reduce dysfunction in cellular membrane metabolism possibly associated with schizophrenia. Bertolino et al..$^{92}$ used proton magnetic resonance spectroscopic imaging $\left({ }^{1} \mathrm{H}-\mathrm{MRSI}\right)$ to measure n-acetylaspartate levels in several brain regions in 23 patients with schizophrenia studied twice, one while on treatment with antipsychotics and another while drug free for at least 2 weeks. The authors reported a significant effect of treatment only in the dorsolateral prefrontal cortex, in which $\mathrm{n}$-acetylaspartate measures were greater during treatment with antipsychotics. These results suggested that antipsychotic drugs improve neuronal biochemistry (n-acetylaspartate is reduced in dorsolateral prefrontal cortex of patients with schizophrenia) ${ }^{46}$ and possibly cellular glutamate specifically in dorsolateral prefrontal cortex.

PET has been used to evaluate the effect of singledose and long-term treatment with antipsychotics on brain glucose metabolism or blood flow. Liddle et al. ${ }^{93}$ used ${ }^{18}$ fluoro-deoxyglucose PET to measure the effect of risperidone on glucose metabolism in a cohort of eight patients with schizophrenia, reporting that a single dose induced glucose metabolism reduction in ventral striatum, thalamus, and frontal cortex; this decrement was also associated with improvement in hallucinations and delusions. Bartlett et al. ${ }^{94}$ measured glucose metabolism with the same tracer in patients with schizophrenia who had been earlier deemed to be responsive $(\mathrm{N}=7)$ or nonresponsive $(\mathrm{N}=7)$ to treatment with antipsychotics. Subjects were scanned with PET the first time after a 3 -week drug-free period and the second time $12 \mathrm{~h}$ after a single dose of haloperidol. The results indicated diffuse 
reductions of glucose metabolism after the haloperidol challenge in nonresponders compared with responders.

Other studies have addressed the long-term effects of antipsychotic treatment. Molina et al.,95 again using ${ }^{18}$ fluoro-deoxyglucose PET, found that 6 months of treatment with risperidone in patients with schizophrenia was associated with slight increases from baseline of glucose metabolism in primary visual area and in right insula. The same group ${ }^{96}$ also studied with the same technique 22 treatment-resistant patients with schizophrenia at baseline and after 6 months of treatment with clozapine, reporting reduction of basal ganglia and increase of occipital glucose metabolism after treatment. Rodriguez et al. ${ }^{97}$ examined 39 treatment-resistant patients with schizophrenia with ${ }^{99} \mathrm{Tc}$-labeled hexamethyl-propyleneaminoxime. Using single-photon emission tomography (SPECT), all patients were studied twice, the first while on first-generation antipsychotics and the second after 6 months of treatment with clozapine. Comparison of the two scans demonstrated increased perfusion in the thalamus, basal ganglia, and dorsolateral prefrontal cortex when on clozapine.

These various PET and SPECT studies were performed during resting conditions (without any specific cognitive challenge), thus possibly limiting understanding of the functional implications of the differential metabolism associated with drug treatment. Other studies have been performed while subjects were engaged in specific cognitive tasks, allowing a more specific investigation of the relationship between changes in brain activity and specific behavioral correlates during treatment. For example, Lahti et al. ${ }^{98}$ used a tone discrimination task and ${ }^{15} \mathrm{O}$ water PET to study the regional cerebral blood flow in 6 patients with schizophrenia and 12 healthy volunteers. Patients were scanned after a mean of 19 days of withdrawal from antipsychotics and again while receiving clozapine and/or haloperidol treatment. The authors reported abnormal activity of the anterior cingulate cortex during the off-drug condition, whereas treatment with clozapine but not with haloperidol normalized activity in the cingulate area. Molina et al. ${ }^{99}$ used ${ }^{18}$ fluoro-deoxyglucose PET to study brain activity during the Continuous Performance Test (mainly evaluating sustained attention) in 17 patients with schizophrenia being treated either with first-generation antipsychotics $(\mathrm{n}=15)$ or risperidone $(\mathrm{n}=2)$, and again while subjects were under 17-24 weeks of treatment with olanzapine. No significant change was found comparing regional cerebral blood flow before and after treatment.

fMRI studies have been generally consistent with these earlier PET studies suggesting functional changes associated with antipsychotic treatment in brain areas involved in the cognitive function under observation. Honey et al. ${ }^{100}$ showed that switching treatment from haloperidol to risperidone in a cohort of 10 patients with schizophrenia was associated with increased activity in prefrontal cortex, supplementary motor area, and parietal cortex during performance of a working memory task. The authors suggested that this effect was possibly associated with relatively reduced $\mathrm{D}_{2}$ receptor antagonism of risperidone relative to haloperidol. Two further fMRI studies have analyzed the effect of antipsychotic treatment on activity of the motor network, previously found to be abnormally lateralized in schizophrenia. ${ }^{101}$ In the first, Stephan et al. ${ }^{102}$ studied six patients with schizophrenia and six matched controls, twice while performing a finger-tapping task. Patients were studied while drug-free and again after 3 weeks of treatment with olanzapine, and the controls with a similar time interval. The results of this study suggested changes in cerebellum functional connectivity (CFC) with other brain regions at the second time point: in particular, olanzapine administration was associated with changes in CFC with prefrontal cortex and medio-dorsal thalamus. Furthermore, olanzapine administration tended to normalize right hemisphere, but not left CFC. Both groups of subjects also showed changes in CFC with motor regions and the authors suggested that the these results may have been due to repetition effects. Bertolino et al. ${ }^{103}$ administered a visually paced motor task during fMRI to 17 patients with schizophrenia at 4 and 8 weeks of treatment with olanzapine. They reported reduced activity of the primary sensory motor cortex after 4 relative to 8 weeks of treatment. Similar analysis on 17 controls performing the task at two time points with a similar time interval did not show any effect in the sensory motor cortex. Analysis of the first time point showed an effect of diagnosis, where patients had reductions of sensory motor cortex activity relative to controls; on the other hand, no effect of diagnosis was found at 8 weeks. However, lateralization of the cortical motor network remained reduced in patients compared with patients even after 8 weeks of treatment. On the basis of these results, the authors suggested that treatment with olanzapine contributes to partially normalize responses in the cortical motor network in patients with schizophrenia. On the other hand, reduced lateralization of the cortical motor network seems to be a trait feature of the disorder.

Finally, one study focused on the effect of antipsychotic treatment on brain networks associated with emotion processing. Stip et al. ${ }^{104}$ treated 12 patients with schizophrenia presenting flat or blunted affect with quetiapine for 5.5 months. All subjects underwent fMRI before and after treatment while passively viewing sad films. The comparison between the two scans showed higher activity in the brainstem at the first time point relative to the second, whereas ventro-medial frontal and orbito-frontal cortices (both involved in emotional regulation) were more activated at the second time point, suggesting potentially beneficial effects of treatment 
with quetiapine in terms of engagement of emotion processing circuitry.

In summary, all these studies suggest that brain morphology, metabolism, and activity may be influenced by antipsychotic treatment, possibly having an impact on neuronal information processing. However, modifications at the neurobiological level do not always imply modifications of the behavioral correlates. ${ }^{103}$ On the other hand, the heterogeneity of the findings suggests that, among other factors, individual variability may differentiate the neurobiological response to treatment. This individual variability is, at least in part, associated with individual genetic features. Therefore, how can we investigate the relationship between genetic variation, brain physiology, behavior, antipsychotic treatment, and schizophrenia?

\section{GENES, BRAIN PHYSIOLOGY, BEHAVIOR, ANTIPSYCHOTIC TREATMENT, AND SCHIZOPHRENIA}

Behavior is associated with relatively specific brain activity (as measured with functional brain imaging), which may vary as a function of individual genetic variability. This line of reasoning has recently inspired studies aiming to assess how genetic factors influence brain activity in response to antipsychotic treatment. Based on the receptors blocked by clozapine, Potkin et al. ${ }^{105}$ studied the potential interaction between treatment with clozapine and D1, D3, $5 \mathrm{HT}_{2 \mathrm{~A}}$, and $5 \mathrm{HT}_{2 \mathrm{C}}$ polymorphisms on brain activity during the Continuous Performance Test. They studied 15 patients with schizophrenia with ${ }^{18}$ fluoro-deoxyglucose PET after 5 weeks of treatment with placebo and again after 5 weeks of clozapine treatment. The authors did not find any effect of $\mathrm{D} 3,5 \mathrm{HT}_{2 \mathrm{~A}}$, and $5 \mathrm{HT}_{2 \mathrm{C}}$ polymorphisms, while they reported an interaction between a D1 polymorphism (located about 1 $\mathrm{kb}$ upstream of the initiation codon) with unknown function, and pharmacological treatment. More specifically, clozapine was associated with generalized decrease in metabolism in frontal, temporal, occipital, and cingulate regions in subjects with the 2,2 D1 genotype, whereas subjects with the 1,2 D1 genotype showed metabolic decrease only in left dorsolateral prefrontal cortex, temporal tip, and parietal areas. No behavioral statistical differences were found between placebo and clozapine treatments. Furthermore, the 2,2 D1 genotype was associated with BPRS score improvement, whereas patients with 1,2 genotype demonstrated an unusual BPRS score worsening with clozapine. Even if these data are consistent with the notion that specific allelic variants may have an impact on glucose brain metabolic changes associated with antipsychotic treatment, it is not clear how this D1 polymorphism may impact on receptor function and dopamine signaling. Therefore, it is difficult to for- mulate an explanation for how these associations with clozapine response. No association has been reported so far between D1 polymorphisms and schizophrenia.

In contrast, recent evidence suggests that the GRM3 gene is associated with schizophrenia ${ }^{43-45}$ and GRM3 polymorphisms may differentially influence brain physiology and behavior (see above). ${ }^{43}$ One study investigated the interaction between GRM3 polymorphisms and antipsychotic treatment. Controlling for COMT val $^{158}$ met genotype, Bertolino et al. ${ }^{106}$ evaluated the effect of 3 GRM3 SNPs (rs6465084, hCV2536213, and rs1468412) on prefrontal function in 24 patients with schizophrenia treated with olanzapine. All patients were scanned with fMRI after 4 and again after 8 weeks of treatment with olanzapine while performing the N-BACK working memory task. Although the behavioral data did not show any difference between genotype groups at both time points, fMRI data analysis revealed a difference: at 4 weeks of treatment, the groups could not be differentiated but by 8 weeks, subjects with risk alleles (previously associated with schizophrenia) had greater dorsolateral prefrontal cortex activity. These findings suggest that the brain phenotype of prefrontal cortical inefficiency (greater engagement in the face of similar behavioral performance) previously demonstrated in schizophrenia is more evident in patients carrying the GRM3 risk alleles. The fact that this phenotype becomes more evident after 8 weeks of treatment suggests that patients carrying the risk allele benefit less from treatment with olanzapine, whereas patients without the risk allele improve efficiency of prefrontal cortical engagement. Because GRM3 receptors directly modulate activity of the glutamate transporter, these data may be intriguing because they directly implicate glutamate signaling. However, once again the effect of these GMR3 polymorphisms on protein structure or activity is not specifically known making it difficult to directly correlate these findings with a specific neurobiological mechanism.

Another study by Bertolino et al. ${ }^{22}$ investigated the potential interaction between COMT val ${ }^{158}$ met genotype and treatment with olanzapine in schizophrenia. In this study, 30 previously untreated patients with schizophrenia received monotherapy with olanzapine for 8 weeks. All subjects were evaluated with the PANSS at baseline as well as after 4 and 8 weeks of treatment. Twenty of the patients also underwent fMRI during the N-BACK working memory task after 4 and 8 weeks of treatment. All data converged in indicating a met allele load effect: met homozygous patients responded (at least 30\% of improvement from baseline) better in terms of PANSSnegative symptoms score compared with both heterozygous and val homozygous subjects after 8 weeks of treatment; working memory performance at the highest load improved more in met homozygous subjects com- 


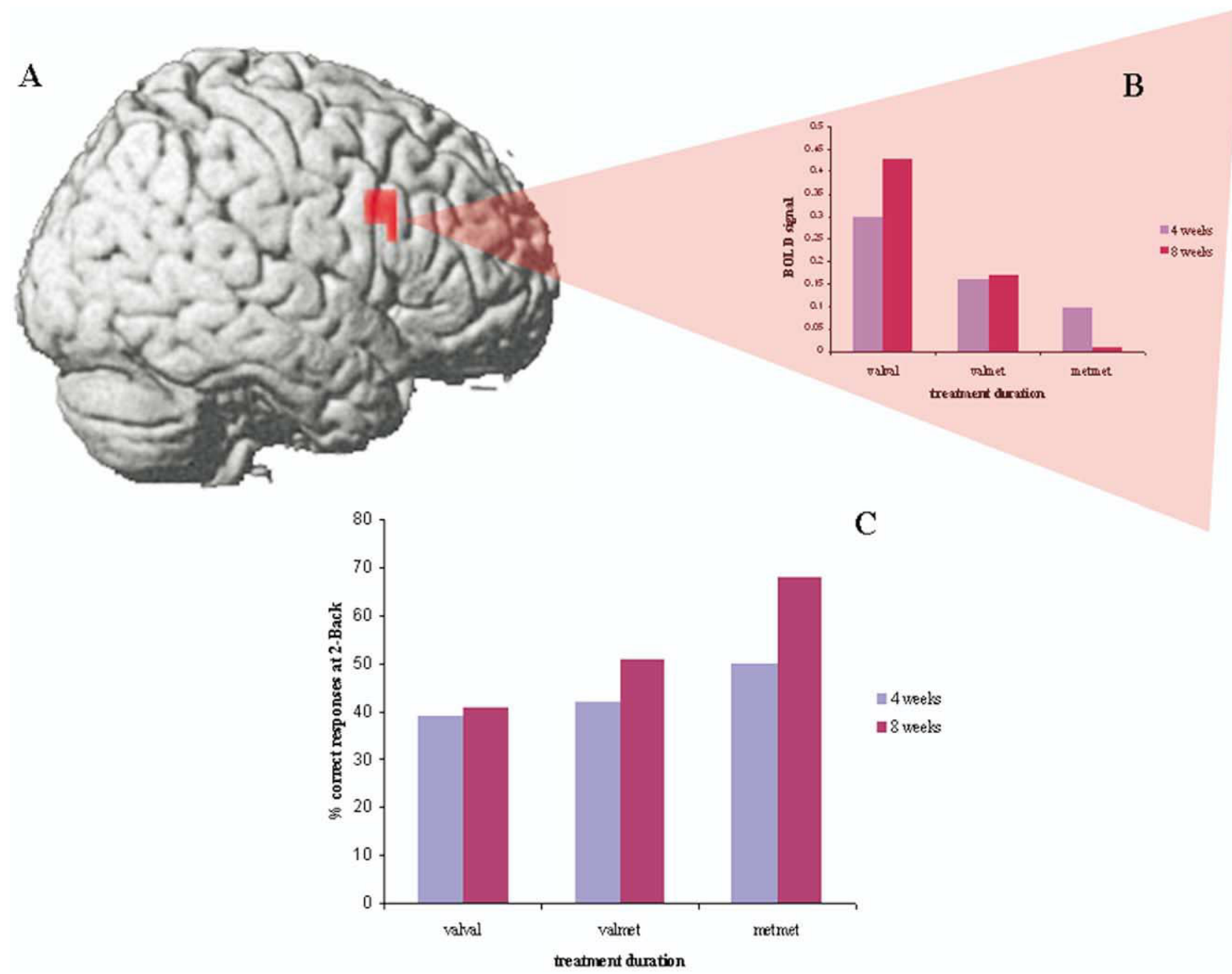

FIG. 2. Effect of COMT val ${ }^{158}$ met genotype on parietal and dorsolateral prefrontal cortical (DLPFC) efficiency. A: fMRI statistical map (sagittal three-dimensional rendering) of the effect of COMT genotype on DLPFC activity during high working memory load within the N-BACK task (2-BACK) in a group of patients with schizophrenia treated for 8 weeks with olanzapine: valval subjects have greater DLPFC activation relative to valmet and metmet subjects after 8 weeks of treatment. B: Plot of the mean fMRI signal change in dorsolateral prefrontal cortex of patients with schizophrenia at 4 and 8 weeks of treatment with olanzapine indicating that Val/Val individuals increase their neuronal activity, Val/Met remain fairly stable, and Met/Met individuals decrease their neuronal activity in spite of significant improvements in performance (greater efficiency). C, Plot of the difference in behavioral accuracy at 2-BACK between 4 and 8 weeks of treatment with olanzapine. At 8 weeks, metmet subjects show reduced BOLD signal in DLPFC in spite of increased behavioral accuracy, suggesting greater prefrontal efficiency. On the other hand, valval subjects slightly increase behavioral accuracy, but also increase DLPFC BOLD signal.

pared with both heterozygous and val homozygous subjects; dorsolateral prefrontal cortical efficiency during working memory (as measured with fMRI) improved more in met homozygous subjects compared with both heterozygous and val homozygous subjects after 8 weeks of treatment. These results suggest that met homozygous subjects benefit more from treatment with olanzapine than heterozygous and val homozygous subjects (FIG. 2).

These data are consistent with the current view of the importance of dopamine signaling and of COMT activity in prefrontal cortex during working memory. Seamans et al. ${ }^{13}$ have suggested that optimal prefrontal function is modulated by a balance between D1 and D2 dopaminer- gic receptor stimulation. In particular, increasing D1/D2 ratio stimulation may provide greater neuronal signal-tonoise ratio with increased neuronal capacity for target representation, limiting the interference of background stimuli. Because schizophrenia is possibly characterized by decreased cortical dopamine levels, ${ }^{109}$ the combined effect of D2 receptor blockade and the increased release of dopamine in prefrontal cortex mediated by secondgeneration antipsychotics such as olanzapine ${ }^{76}$ may lead to increased D1/D2 ratio stimulation. This effect may in turn increase signal to noise ratio thus increasing working memory performance. This interpretation is consistent with current speculation about the possibility that the val allele is associated with reduced cortical levels of 


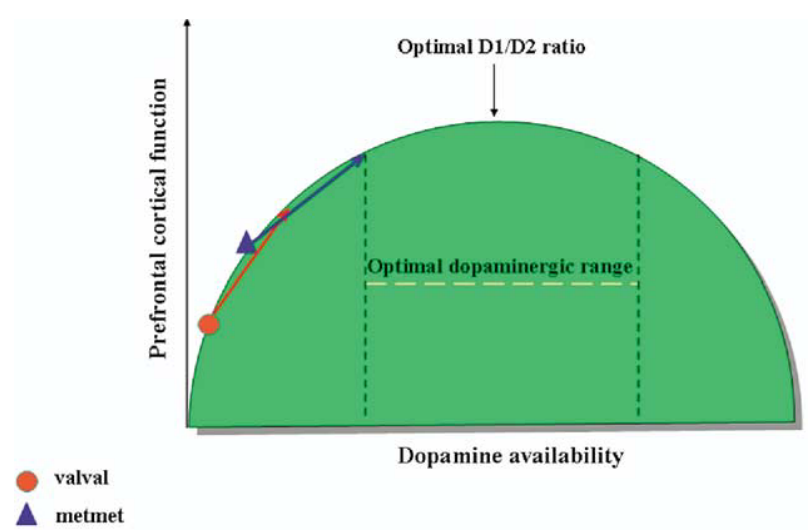

FIG. 3. Hypothetical effect of COMT val ${ }^{158}$ met genotype in contributing to determine individual variability in response to treatment with second-generation antipsychotics in schizophrenia. Second-generation antipsychotics increase dopamine levels in prefrontal cortex and they might also increase dopamine receptor D1/D2 ratio, thus improving prefrontal cortex function. Given the slower inactivation of prefrontal dopamine of the COMT metmet enzyme, these subjects may benefit from greater prefrontal dopaminergic signaling in terms of prefrontal cortex efficiency compared with valval subjects.

dopamine signaling relative to the met allele. ${ }^{108}$ Therefore, met carriers may have greater benefit from olanzapine treatment because of slower inactivation of cortical dopamine and improved D1/D2 ratio signaling (FIG. 3). In summary, this study supports a broader conceptual approach about the investigation of the interaction among genetic polymorphisms, brain physiology, behavior, and antipsychotic treatment. Further studies in schizophrenia following this approach are needed to better understand the basis of individual variability in response to pharmacological treatment.

\section{AFTERWORD}

The first conclusion to be drawn from the studies here reviewed is that preliminary efforts to study how individual genetic factors may contribute to individual variability in response to treatment with antipsychotic drugs has commenced. The field of pharmacogenetics in schizophrenia clearly needs to advance in many different aspects. Several fundamental issues need to be addressed before we can provide definitive answers to patients and clinicians. ${ }^{107}$ These issues can be identified in two broad areas concerning 1) clinical research design and 2) genomic approaches.

Without considering the limited conceptual and statistical power of retrospective studies, factors currently limiting our understanding of pharmacogenetic data obtained from clinical research data in schizophrenia include: the choice of study duration (short $v s$ long term); the clinical phase of the disorder (acute re-exacerbation $v s$ chronic symptoms); the design of the study (double blind, placebo controlled $v s$ open label studies); the choice of antipsychotics (first vs second generation); sample size sufficiently powered; drug company and public health agency strategies; and, most of all, the phenotype of interest. At least in the field of pharmacogenetics, several of these issues are correlated with the crucial choice of the phenotype. Schizophrenia is a heterogeneous disorder with a heterogeneous clinical phenotype whose symptoms are most likely emergent phenomena. ${ }^{110}$ The clinical presentation is also complicated by issues of genetically associated low penetrance, heterogeneity, and phenocopies. If variability of the phenotype under investigation is too large, the search for genes contributing to the individual manifestation of the schizophrenia phenotype or of the individual response to pharmacological treatment is unlikely to be successful. Rating scales have been largely used to assess the clinical symptoms of schizophrenia and they now represent, along with the Diagnostic and Statistical Manual (DSM), the common language spoken by research psychiatrists all over the world. However, along with the inherent subjectivity of the ratings, the clinical symptoms of schizophrenia are heterogeneous and may vary over time in the single patient making it difficult to precisely capture the genetic individuality of our patients at the level of clinical symptoms. Moreover, genes encode for proteins but do not encode for delusions, hallucinations, and negative symptoms. Therefore, use of intermediate phenotypes may be of help in limiting the drawbacks from several of the issues outlined above. A valid intermediate phenotype is by definition a trait feature of the disorder with limited variation associated with state of the disease. Therefore, choice of an intermediate phenotype should by definition control for differences associated with the clinical phase of the disorder and with choice of the duration of the study. Moreover, intermediate phenotypes are objective neurobiological measures for which there is little or no margin for subjective error. In this way, the relevance of controlled versus uncontrolled trials becomes much less important. Of course, every biological measurement made on an individual is not a genetically determined intermediate phenotype. As used here, and as rarely validated thus far in the literature, the term intermediate phenotype is meant to represent a biological trait related to genes of interest. In this line of reasoning, functional neuroimaging brain phenotypes may provide several advantages as compared with other intermediate and clinical phenotypes. First of all, functional neuroimaging can be performed in living human subjects allowing in vivo measures of brain function. Moreover, fMRI and PET permit acquisition of information that is relatively specific in terms of the neurobiological systems involved. For example, fMRI allows evaluation of the circuitry involved in performing specific cognitive functions. For several of these cognitive functions, studies in rodents and in nonhuman primates have also provided detailed information about the 
underlying cellular and systems neurobiology. Therefore, the possibility of combining the in vivo data with known cellular information allows elaboration of specific and testable hypotheses about the neurobiological effects of genetic variation in individuals. This possibility confers added value to the information obtained so that it is easier to obtain neurobiological information that is directly relevant to the pathophysiology of brain disorders and to the individual response to pharmacological treatments. Another relevant advantage of functional neuroimaging phenotypes is given by the robust statistical power of these techniques. For example, fMRI studies often give results with large effect size of the differences between groups. The differences thus described at the neurobiological level can be obtained in relatively small sample populations (especially in the absence of significant differences in behavioral measures), underscoring the power of a direct assay of brain function (i.e., fMRI) to identify phenotypes related to gene polymorphisms. Therefore, the application of such techniques appears to provide a unique opportunity to explore and evaluate the functional impact of brain-relevant genetic polymorphisms more rapidly and with greater sensitivity than existing behavioral assessments. In this way, it is clear how statistically robust information can be obtained with relatively smaller samples of patients compared with the sample size needed when using only clinical phenotypes. Therefore, use of functional imaging intermediate phenotypes may provide a means for reducing error-related phenotypic variability among patients, thus making it more feasible to look at the effects of genetic factors.

If for clinical research design we may have fairly clear ideas on how to advance the field of pharmacogenetics, for genomic approaches we seem to have more questions than answers. The first question is whether one should use genomic-wide hypothesis-free approaches versus a strategy using candidate genes. It is clear that genomewide studies have several advantages but, at present, this approach is limited by costs, impracticality of acquiring sufficiently large samples, and feasibility across laboratories. Another problem posed by this approach at present is that, with our limited knowledge about the pathophysiology of the disorder, we may not be able to fully appreciate and understand results based solely on statistical criteria without clear hypotheses. The alternative is to use candidate gene approaches, as described above. However, there are important open questions for this approach, too. The first question is which genes one should go after: causative genes, drug receptor genes, or modifier genes. It seems fairly straightforward that if causative genes have functional variants that impact on the neurobiology of the disorder, these can be the most informative genes also about the individuality of response to treatment. However, whereas evaluation of one SNP or one haplotype from one gene is informative about the main effect of that gene, this approach is blind to the genetic background on which a specific gene exerts its effect, including the possibility of additive effects or of epistasis with other genes or environmental factors. In this sense, studies evaluating main effects of genes should at least try and match for polymorphisms in other genes with known effects. Moreover, in an ideal world sample sizes should be powered to look at the effect of several genes together in a specific neurobiological pathway. In this regard, it is clear that examination of functional gene variants becomes much more informative about the neurobiology of the disorder or of the response to treatment. Additional questions in the genomic realm include the frequency of gene variants in the population studied as well as the statistical approaches used. As for the latter, we will inevitably have to face the fact that the genes involved in determining the pathophysiology of schizophrenia and the response to treatment are likely to have small effects. Therefore, once again use of functional neuroimaging phenotypes may be of great help for the reasons outlined above.

In conclusion, the field of pharmacogenetics in schizophrenia is just beginning. Clinical and genomic issues are critically linked to the potential development of improved strategies for determining a priori who is going to respond to which drug. We believe that use of functional neuroimaging phenotypes may be of great relevance to allow for further progress of the field of pharmacogenetics in schizophrenia.

\section{REFERENCES}

1. McGuffin P, Riley B, Plomin R. Genomics and behavior. Toward behavioral genomics. Science 5507:1232-1249, 2001.

2. Harrison PJ, Weinberger DR. Schizophrenia genes, gene expression, and neuropathology: on the matter of their convergence. Mol Psychiatry 1:40-68, 2005.

3. Lewis CM, Levinson DF, Wise LH, Delisi LE, Straub RE, Hovatta I, et al. Genome scan meta-analysis of schizophrenia and bipolar disorder. Part II: schizophrenia. Am J Hum Genet 1:3448, 2003.

4. Badner JA, Gershon ES. Meta-analysis of whole-genome linkage scans of bipolar disorder and schizophrenia. Mol Psychiatry 4:405-411, 2002.

5. Weinberger DR. Implications of normal brain development for the pathogenesis of schizophrenia. Arch Gen Psychiatry 7:660669, 1987.

6. Sesack SR, Hawrylak VA, Matus C, Guido MA, Levey AI. Dopamine axon varicosities in the prelimbic division of the rat prefrontal cortex exhibit sparse immunoreactivity for the dopamine transporter. J Neurosci 7:2697-2708, 1998.

7. Moron JA, Brockington A, Wise RA, Rocha BA, Hope BT. Dopamine uptake through the norepinephrine transporter in brain regions with low levels of the dopamine transporter: evidence from knock-out mouse lines. J Neurosci 2:389-395, 2002.

8. Shen HW, Hagino Y, Kobayashi H, Shinohara-Tanaka K, Ikeda $\mathrm{K}$, Yamamoto $\mathrm{H}$, et al. Regional differences in extracellular dopamine and serotonin assessed by in vivo microdialysis in mice lacking dopamine and/or serotonin transporters. Neuropsychopharmacology 10:1790-1799, 2004.

9. Tunbridge EM, Bannerman DM, Sharp T, Harrison PJ. Catecholo-methyltransferase inhibition improves set-shifting performance and elevates stimulated dopamine release in the rat prefrontal cortex. J Neurosci 23:5331-5335, 2004. 
10. Liljequist R, Haapalinna A, Ahlander M, Li YH, Mannisto PT. Catechol O-methyltransferase inhibitor tolcapone has minor influence on performance in experimental memory models in rats. Behav Brain Res 2:195-202, 1997.

11. Gogos JA, Morgan M, Luine V, Santha M, Ogawa S, Pfaff D, et al. Catechol-O-methyltransferase-deficient mice exhibit sexually dimorphic changes in catecholamine levels and behavior. Proc Natl Acad Sci USA 17:9991-9996, 1998.

12. Mannisto PT, Kaakkola S. Catechol-O-methyltransferase (COMT): biochemistry, molecular biology, pharmacology, and clinical efficacy of the new selective COMT inhibitors. Pharmacol Rev 4:593-628, 1999.

13. Seamans JK, Yang CR. The principal features and mechanisms of dopamine modulation in the prefrontal cortex. Prog Neurobiol $1: 1-58,2004$.

14. Goldman-Rakic PS. The cortical dopamine system: role in memory and cognition. Adv Pharmacol 707-711, 1998.

15. Egan MF, Goldberg TE, Kolachana BS, Callicott JH, Mazzanti CM, Straub RE, et al. Effect of COMT Val108/158 Met genotype on frontal lobe function and risk for schizophrenia. Proc Natl Acad Sci USA 12:6917-6922, 2001.

16. Goldberg TE, Egan MF, Gscheidle T, Coppola R, Weickert T, Kolachana BS, et al. Executive subprocesses in working memory: relationship to catechol-O-methyltransferase Val158Met genotype and schizophrenia. Arch Gen Psychiatry 9:889-896, 2003.

17. Blasi G, Mattay VS, Bertolino A, Elvevag B, Callicott JH, Das S, et al. Effect of catechol-O-methyltransferase val158met genotype on attentional control. J Neurosci 20:5038-5045, 2005.

18. Bearden CE, Jawad AF, Lynch DR, Sokol S, Kanes SJ, McDonald-McGinn DM, et al. Effects of a functional COMT polymorphism on prefrontal cognitive function in patients with 22q11.2 deletion syndrome. Am J Psychiatry 9:1700-1702, 2004.

19. Diamond A, Briand L, Fossella J, Gehlbach L. Genetic and neurochemical modulation of prefrontal cognitive functions in children. Am J Psychiatry 1:125-132, 2004

20. Callicott JH, Bertolino A, Mattay VS, Langheim FJ, Duyn J, Coppola R, et al. Physiological dysfunction of the dorsolateral prefrontal cortex in schizophrenia revisited. Cereb Cortex 11: 1078-1092, 2000

21. Manoach DS, Gollub RL, Benson ES, Searl MM, Goff DC, Halpern E, et al. Schizophrenic subjects show aberrant fMRI activation of dorsolateral prefrontal cortex and basal ganglia during working memory performance. Biol Psychiatry 2:99-109, 2000.

22. Bertolino A, Caforio G, Blasi G, De Candia M, Latorre V, Petruzzella V, et al. Interaction of COMT Val108/158 Met genotype and olanzapine treatment on prefrontal cortical function in patients with schizophrenia. Am J Psychiatry 10:1798-1805, 2004.

23. Ho BC, Wassink TH, O'Leary DS, Sheffield VC, Andreasen NC. Catechol-O-methyl transferase $\mathrm{Val}^{158}$ Met gene polymorphism in schizophrenia: working memory, frontal lobe MRI morphology and frontal cerebral blood flow. Mol Psychiatry 3:229:287-298, 2005.

24. St Clair D, Blackwood D, Muir W, Carothers A, Walker M, Spowart G, et al. Association within a family of a balanced autosomal translocation with major mental illness. Lancet 8706: 13-16, 1990.

25. Devon RS, Anderson S, Teague PW, Burgess P, Kipari TM, Semple CA, et al. Identification of polymorphisms within Disrupted in Schizophrenia 1 and Disrupted in Schizophrenia 2, and an investigation of their association with schizophrenia and bipolar affective disorder. Psychiatr Genet 2:71-78, 2001.

26. Hennah W, Varilo T, Kestila M, Paunio T, Arajarvi R, Haukka J, et al. Haplotype transmission analysis provides evidence of association for DISC1 to schizophrenia and suggests sex-dependent effects. Hum Mol Genet 23:3151-3159, 2003.

27. Ekelund J, Hennah W, Hiekkalinna T, Parker A, Meyer J, Lonnqvist J, et al. Replication of 1q42 linkage in Finnish schizophrenia pedigrees. Mol Psychiatry 11:1037-1041, 2004.

28. Hodgkinson CA, Goldman D, Jaeger J, Persaud S, Kane JM, Lipsky RH, et al. Disrupted in Schizophrenia 1 (DISC1): association with schizophrenia, schizoaffective disorder, and bipolar disorder. Am J Hum Genet 5:862-872, 2004.
29. Sachs NA, Sawa A, Holmes SE, Ross CA, Delisi LE, Margolis RL. A frameshift mutation in disrupted in schizophrenia 1 in an American family with schizophrenia and schizoaffective disorder. Mol Psychiatry 10:758-764, 2005.

30. Thomson PA, Wray NR, Millar JK, Evans KL, Hellard SL, Condie A, et al. Association between the TRAX/DISC locus and both bipolar disorder and schizophrenia in the Scottish population. Mol Psychiatry 7:616, 657-668, 2005.

31. Morris JA, Kandpal G, Ma L, Austin CP. DISC1 (Disrupted-InSchizophrenia 1) is a centrosome-associated protein that interacts with MAP1A, MIPT3, ATF4/5 and NUDEL: regulation and loss of interaction with mutation. Hum Mol Genet 13:1591-1608, 2003.

32. Austin CP, Ky B, Ma L, Morris JA, Shughrue PJ. Expression of Disrupted-In-Schizophrenia-1, a schizophrenia-associated gene, is prominent in the mouse hippocampus throughout brain development. Neuroscience 1:3-10, 2004.

33. Callicott JH, Straub RE, Pezawas L, Egan MF, Mattay VS, Hariri $\mathrm{AR}$, et al. Variation in DISC1 affects hippocampal structure and function and increases risk for schizophrenia. Proc Natl Acad Sci USA 24:8627-8632, 2005

34. Bunney BS, Chiodo LA, Grace AA. Midbrain dopamine system electrophysiological functioning: a review and new hypothesis. Synapse 2:79-94, 1991.

35. Deakin JF, Slater P, Simpson MD, Gilchrist AC, Skan WJ, Royston $\mathrm{MC}$, et al. Frontal cortical and left temporal glutamatergic dysfunction in schizophrenia. J Neurochem 6:1781-1786, 1989.

36. Nishikawa T, Takashima M, Toru M. Increased [3H]kainic acid binding in the prefrontal cortex in schizophrenia. Neurosci Lett 3:245-250, 1983.

37. Tsai G, Passani LA, Slusher BS, Carter R, Baer L, Kleinman JE, et al. Abnormal excitatory neurotransmitter metabolism in schizophrenic brains. Arch Gen Psychiatry 10:829-836, 1995.

38. Cartmell J, Schoepp DD. Regulation of neurotransmitter release by metabotropic glutamate receptors. J Neurochem 3:889-907, 2000.

39. Aronica E, Gorter JA, Ijlst-Keizers H, Rozemuller AJ, Yankaya B, Leenstra S, et al. Expression and functional role of mGluR3 and mGluR5 in human astrocytes and glioma cells: opposite regulation of glutamate transporter proteins. Eur J Neurosci 10: 2106-2118, 2003.

40. Rothstein JD, Dykes-Hoberg M, Pardo CA, Bristol LA, Jin L, Kuncl RW, et al. Knockout of glutamate transporters reveals a major role for astroglial transport in excitotoxicity and clearance of glutamate. Neuron 3:675-686, 1996.

41. Moghaddam B, Adams BW. Reversal of phencyclidine effects by a group II metabotropic glutamate receptor agonist in rats. Science 5381:1349-1352, 1998.

42. Ohnuma T, Tessler S, Arai H, Faull RL, McKenna PJ, Emson PC. Gene expression of metabotropic glutamate receptor 5 and excitatory amino acid transporter 2 in the schizophrenic hippocampus. Brain Res Mol Brain Res 1-2:24-31, 2000.

43. Egan MF, Straub RE, Goldberg TE, Yakub I, Callicott JH, Hariri AR, et al. Variation in GRM3 affects cognition, prefrontal glutamate, and risk for schizophrenia. Proc Natl Acad Sci USA 34:12604-12609, 2004.

44. Fujii Y, Shibata H, Kikuta R, Makino C, Tani A, Hirata N, et al. Positive associations of polymorphisms in the metabotropic glutamate receptor type 3 gene (GRM3) with schizophrenia. Psychiatr Genet 2:71-76, 2003.

45. Chen Q, He G, Wu S, Xu Y, Feng G, Li Y, et al. A case-control study of the relationship between the metabotropic glutamate receptor 3 gene and schizophrenia in the Chinese population. Schizophr Res 1:21-26, 2005.

46. Bertolino A, Nawroz S, Mattay VS, Barnett AS, Duyn JH, Moonen CT, et al. Regionally specific pattern of neurochemical pathology in schizophrenia as assessed by multislice proton magnetic resonance spectroscopic imaging. Am $J$ Psychiatry 12:1554-1563, 1996.

47. Marti SB, Cichon S, Propping P, Nothen M. Metabotropic glutamate receptor 3 (GRM3) gene variation is not associated with schizophrenia or bipolar affective disorder in the German population. Am J Med Genet 1:46-50, 2002. 
48. Norton N, Williams HJ, Dwyer S, Ivanov D, Preece AC, Gerrish A, et al. No evidence for association between polymorphisms in GRM3 and schizophrenia. BMC Psychiatry 1:23, 2005.

49. Lu B, Gottschalk W. Modulation of hippocampal synaptic transmission and plasticity by neurotrophins. Prog Brain Res 128: 231-241, 2000.

50. Poo MM. Neurotrophins as synaptic modulators. Nat Rev Neurosci 1:24-32, 2001.

51. Gottschalk W, Pozzo-Miller LD, Figurov A, Lu B. Presynaptic modulation of synaptic transmission and plasticity by brain-derived neurotrophic factor in the developing hippocampus. $J$ Neurosci 17:6830-6839, 1998

52. Gottschalk WA, Jiang H, Tartaglia N, Feng L, Figurov A, Lu B. Signaling mechanisms mediating BDNF modulation of synaptic plasticity in the hippocampus. Learn Mem 3:243-256, 1999.

53. Jovanovic JN, Czernik AJ, Fienberg AA, Greengard P, Sihra TS. Synapsins as mediators of BDNF-enhanced neurotransmitter release. Nat Neurosci 4:323-329, 2000.

54. Pozzo-Miller LD, Gottschalk W, Zhang L, McDermott K, Du J, Gopalakrishnan R, et al. Impairments in high-frequency transmission, synaptic vesicle docking, and synaptic protein distribution in the hippocampus of BDNF knockout mice. J Neurosci 12: 4972-4983, 1999.

55. Xu B, Gottschalk W, Chow A, Wilson RI, Schnell E, Zang K, et al. The role of brain-derived neurotrophic factor receptors in the mature hippocampus: modulation of long-term potentiation through a presynaptic mechanism involving TrkB. J Neurosci 18:6888-6897, 2000.

56. Linnarsson S, Bjorklund A, Ernfors P. Learning deficit in BDNF mutant mice. Eur J Neurosci 12:2581-2587, 1997.

57. Minichiello L, Korte M, Wolfer D, Kuhn R, Unsicker K, Cestari $\mathrm{V}$, et al. Essential role for TrkB receptors in hippocampus-mediated learning. Neuron 2:401-414, 1999.

58. Mizuno M, Yamada K, Olariu A, Nawa H, Nabeshima T. Involvement of brain-derived neurotrophic factor in spatial memory formation and maintenance in a radial arm maze test in rats. J Neurosci 18:7116-7121, 2000.

59. Angelucci F, Brene S, Mathe AA. BDNF in schizophrenia, depression and corresponding animal models. Mol Psychiatry 4:345-352, 2005.

60. Callicott JH, Egan MF, Bertolino A, Mattay VS, Langheim FJ, Frank JA, et al. Hippocampal $\mathrm{N}$-acetyl aspartate in unaffected siblings of patients with schizophrenia: a possible intermediate neurobiological phenotype. Biol Psychiatry 10:941-950, 1998.

61. Hattori M, Kunugi H, Akahane A, Tanaka H, Ishida S, Hirose T, et al. Novel polymorphisms in the promoter region of the neurotrophin-3 gene and their associations with schizophrenia. Am J Med Genet 3:304-309, 2002.

62. Jonsson E, Brene S, Zhang XR, Nimgaonkar VL, Tylec A, Schalling $\mathrm{M}$, et al. Schizophrenia and neurotrophin-3 alleles. Acta Psychiatr Scand 5:414-419, 1997.

63. Szekeres G, Juhasz A, Rimanoczy A, Keri S, Janka Z. The C270T polymorphism of the brain-derived neurotrophic factor gene is associated with schizophrenia. Schizophr Res 1:15-18, 2003.

64. Egan MF, Kojima M, Callicott JH, Goldberg TE, Kolachana BS, Bertolino A, et al. The BDNF val ${ }^{66}$ met polymorphism affects activity-dependent secretion of BDNF and human memory and hippocampal function. Cell 2:257-269, 2003.

65. Neves-Pereira M, Cheung JK, Pasdar A, Zhang F, Breen G, Yates $\mathrm{P}$, et al. BDNF gene is a risk factor for schizophrenia in a Scottish population. Mol Psychiatry 2:208-212, 2005.

66. Szczepankiewicz A, Skibinska M, Czerski PM, Kapelski P, Leszczynska-Rodziewicz A, Slopien A, et al. No association of the brain-derived neurotrophic factor (BDNF) gene C-270T polymorphism with schizophrenia. Schizophr Res 2-3:187-193, 2005.

67. de Krom M, Bakker SC, Hendriks J, van Elburg A, Hoogendoorn M, Verduijn W, et al. Polymorphisms in the brain-derived neurotrophic factor gene are not associated with either anorexia nervosa or schizophrenia in Dutch patients. Psychiatr Genet 2:81, 2005.

68. Hariri AR, Goldberg TE, Mattay VS, Kolachana BS, Callicott JH, Egan MF, et al. Brain-derived neurotrophic factor $\mathrm{val}^{66}$ met polymorphism affects human memory-related hippocampal activity and predicts memory performance. J Neurosci 17:6690-6694, 2003.

69. Pezawas L, Verchinski BA, Mattay VS, Callicott JH, Kolachana BS, Straub RE, et al. The brain-derived neurotrophic factor $\mathrm{val}^{6{ }^{6}}$ met polymorphism and variation in human cortical morphology. J Neurosci 45:10099-10102, 2004.

70. Szeszko PR, Lipsky R, Mentschel C, Robinson D, Gunduz-Bruce $\mathrm{H}$, Sevy S, et al. Brain-derived neurotrophic factor val ${ }^{66}$ met polymorphism and volume of the hippocampal formation. Mol Psychiatry 7:631-636, 2005.

71. Malhotra AK, Murphy GM Jr, Kennedy JL. Pharmacogenetics of psychotropic drug response. Am J Psychiatry 5:780-796, 2004.

72. Schafer M, Rujescu D, Giegling I, Guntermann A, Erfurth A, Bondy B, et al. Association of short-term response to haloperidol treatment with a polymorphism in the dopamine $\mathrm{D}(2)$ receptor gene. Am J Psychiatry 5:802-804, 2001.

73. Suzuki A, Mihara K, Kondo T, Tanaka O, Nagashima U, Otani K, et al. The relationship between dopamine D2 receptor polymorphism at the Taq1 A locus and therapeutic response to nemonapride, a selective dopamine antagonist, in schizophrenic patients. Pharmacogenetics 4:335-341, 2000.

74. Suzuki A, Kondo T, Mihara K, Yasui-Furukori N, Ishida M, Furukori H, et al. The $-141 \mathrm{C}$ Ins/Del polymorphism in the dopamine D2 receptor gene promoter region is associated with anxiolytic and antidepressive effects during treatment with dopamine antagonists in schizophrenic patients. Pharmacogenetics 6:545-550, 2001

75. Arranz MJ, Li T, Munro J, Liu X, Murray R, Collier DA, et al. Lack of association between a polymorphism in the promoter region of the dopamine-2 receptor gene and clozapine response. Pharmacogenetics 6:481-484, 1998.

76. Kapur S, Agid O, Mizrahi R, Li M. How anitpsychotics workfrom receptors to reality. NeuroRx 3:10-21, 2006.

77. Gessa GL, Devoto P, Diana M, Flore G, Melis M, Pistis M. Dissociation of haloperidol, clozapine, and olanzapine effects on electrical activity of mesocortical dopamine neurons and dopamine release in the prefrontal cortex. Neuropsychopharmacology 6:642-649, 2000.

78. Diaz-Asper C, Goldberg T. COMT polymorphism and prefrontal cognitive function. NeuroRx 3:97-105, 2006.

79. Weickert TW, Goldberg TE, Mishara A, Apud JA, Kolachana BS, Egan MF, et al. Catechol-O-methyltransferase val108/ 158 met genotype predicts working memory response to antipsychotic medications. Biol Psychiatry 9:677-682, 2004.

80. Bishop JR, Ellingrod VL, Moline J, Miller D. Association between the polymorphic GRM3 gene and negative symptom improvement during olanzapine treatment. Schizophr Res 77:25360, 2005.

81. Krebs MO, Guillin O, Bourdell MC, Schwartz JC, Olie JP, Poirier $\mathrm{MF}$, et al. Brain derived neurotrophic factor (BDNF) gene variants association with age at onset and therapeutic response in schizophrenia. Mol Psychiatry 5:558-562, 2000.

82. Hong CJ, Yu YW, Lin CH, Tsai SJ. An association study of a brain-derived neurotrophic factor $\mathrm{Val}^{66} \mathrm{Met}$ polymorphism and clozapine response of schizophrenic patients. Neurosci Lett 3:206-208, 2003.

83. Anttila S, Illi A, Kampman O, Mattila KM, Lehtimaki T, Leinonen E. Lack of association between two polymorphisms of brain-derived neurotrophic factor and response to typical neuroleptics. J Neural Transm 7:885-890, 2005.

84. Corson PW, Nopoulos P, Miller DD, Arndt S, Andreasen NC. Change in basal ganglia volume over 2 years in patients with schizophrenia: typical versus atypical neuroleptics. Am J Psychiatry 8:1200-1204, 1999.

85. Scheepers FE, de Wied CC, Hulshoff Pol HE, van de Flier W, van der Linden JA, Kahn RS. The effect of clozapine on caudate nucleus volume in schizophrenic patients previously treated with typical antipsychotics. Neuropsychopharmacology 1:47-54, 2001.

86. Scheepers FE, Gispen de Wied CC, Hulshoff Pol HE, Kahn RS Effect of clozapine on caudate nucleus volume in relation to symptoms of schizophrenia. Am J Psychiatry 4:644-646, 2001.

87. Lang DJ, Kopala LC, Vandorpe RA, Rui Q, Smith GN, Goghari 
VM, et al. An MRI study of basal ganglia volumes in first-episode schizophrenia patients treated with risperidone. Am J Psychiatry 4:625-631, 2001.

88. Lang DJ, Kopala LC, Vandorpe RA, Rui Q, Smith GN, Goghari $\mathrm{VM}$, et al. Reduced basal ganglia volumes after switching to olanzapine in chronically treated patients with schizophrenia. Am J Psychiatry 10:1829-1836, 2004.

89. Lieberman JA, Tollefson GD, Charles C, Zipursky R, Sharma T, Kahn RS, et al. Antipsychotic drug effects on brain morphology in first-episode psychosis. Arch Gen Psychiatry 4:361-370, 2005.

90. Dorph-Petersen KA, Pierri JN, Perel JM, Sun Z, Sampson AR, Lewis DA. The influence of chronic exposure to antipsychotic medications on brain size before and after tissue fixation: a comparison of Haloperidol and Olanzapine in Macaque monkeys. Neuropsychopharmacology 9:1649-1661, 2005.

91. Fukuzako H, Fukuzako T, Kodama S, Hashiguchi T, Takigawa M, Fujimoto T. Haloperidol improves membrane phospholipid abnormalities in temporal lobes of schizophrenic patients. Neuropsychopharmacology 4:542-549, 1999.

92. Bertolino A, Callicott JH, Mattay VS, Weidenhammer KM, Rakow R, Egan MF, et al. The effect of treatment with antipsychotic drugs on brain $\mathrm{N}$ - acetylaspartate measures in patients with schizophrenia. Biol Psychiatry 1:39-46, 2001.

93. Liddle PF, Lane CJ, Ngan ET. Immediate effects of risperidone on cortico-striato-thalamic loops and the hippocampus. Br J Psychiatry 402-407, 2000

94. Bartlett EJ, Brodie JD, Simkowitz P, Schlosser R, Dewey SL, Lindenmayer JP, et al. Effect of a haloperidol challenge on regional brain metabolism in neuroleptic-responsive and nonresponsive schizophrenic patients. Am J Psychiatry 3:337-343, 1998.

95. Molina V, Gispert JD, Reig S, Sanz J, Pascau J, Santos A, et al. Cerebral metabolism and risperidone treatment in schizophrenia. Schizophr Res 1:1-7, 2003.

96. Molina V, Gispert JD, Reig S, Sanz J, Pascau J, Santos A, et al. Cerebral metabolic changes induced by clozapine in schizophrenia and related to clinical improvement. Psychopharmacology (Berl ) 1:17-26, 2005.

97. Rodriguez VM, Andree RM, Castejon MJ, Zamora ML, Alvaro PC, Delgado JL, et al. Fronto-striato-thalamic perfusion and clozapine response in treatment-refractory schizophrenic patients. A 99mTc-HMPAO study. Psychiatry Res 1:51-61, 1997.

98. Lahti AC, Holcomb HH, Weiler MA, Medoff DR, Frey KN, Hardin M, et al. Clozapine but not haloperidol re-establishes normal task-activated rCBF patterns in schizophrenia within the anterior cingulate cortex. Neuropsychopharmacology 1:171-178, 2004.
99. Molina V, Gispert JD, Reig S, Pascau J, Martinez R, Sanz J, et al. Olanzapine-induced cerebral metabolic changes related to symptom improvement in schizophrenia. Int Clin Psychopharmacol 1:13-18, 2005.

100. Honey GD, Bullmore ET, Soni W, Varatheesan M, Williams SC, Sharma T. Differences in frontal cortical activation by a working memory task after substitution of risperidone for typical antipsychotic drugs in patients with schizophrenia. Proc Natl Acad Sci USA 23:13432-13437, 1999.

101. Mattay VS, Callicott JH, Bertolino A, Santha AK, Tallent KA, Goldberg TE, et al. Abnormal functional lateralization of the sensorimotor cortex in patients with schizophrenia. Neuroreport 13:2977-2984, 1997.

102. Stephan KE, Magnotta VA, White T, Arndt S, Flaum M, O'Leary DS, et al. Effects of olanzapine on cerebellar functional connectivity in schizophrenia measured by fMRI during a simple motor task. Psychol Med 6:1065-1078, 2001.

103. Bertolino A, Blasi G, Caforio G, Latorre V, De Candia M, Rubino $\mathrm{V}$, et al. Functional lateralization of the sensorimotor cortex in patients with schizophrenia: effects of treatment with olanzapine. Biol Psychiatry 3:190-197, 2004.

104. Stip E, Fahim C, Mancini-Marie A, Bentaleb LA, Mensour B, Mendrek A, et al. Restoration of frontal activation during a treatment with quetiapine: an fMRI study of blunted affect in schizophrenia. Prog Neuropsychopharmacol Biol Psychiatry 1:21-26, 2005.

105. Potkin SG, Basile VS, Jin Y, Masellis M, Badri F, Keator D, et al. D1 receptor alleles predict PET metabolic correlates of clinical response to clozapine. Mol Psychiatry 1:109-113, 2003.

106. Bertolino A, Caforio G, Petruzzella V, Latorre V, Rubino V, Dimalta $S$, et al. GRM3 genotype and olanzapine treatment: Differential effects on prefrontal cortical function during working memory in patients with schizophrenia. Biol Psychiatry 8:S293, 2005.

107. Abi-Dargham A, Mawlawi O, Lombardo I, Gil R, Martinez D, Huang Y, et al. Prefrontal dopamine D1 receptors and working memory in schizophrenia. J Neurosci 9:3708-3719, 2002.

108. Bilder RM, Volavka J, Lachman HM, Grace AA. The catecholO-methyltransferase polymorphism: relations to the tonic-phasic dopamine hypothesis and neuropsychiatric phenotypes. Neuropsychopharmacology 11:1943-1961, 2004.

109. Stahl S. Finding what you are not looking for: strategies for developing novel treatments in psychiatry. NeuroRx 3:3-9, 2006.

110. Goldberg TE, Weinberger DR. Genes and the parsing of cognitive processes. Trends Cogn Sci 7:325-335, 2004. 